\title{
Crescimento de palma forrageira em função de diferentes métodos de propagação
}

\section{vegetativa}

\author{
Forage cactus growth as a function of different vegetative propagation methods \\ Crecimiento de la palma forrajera en función de diferentes métodos de propagación vegetativa
}

Recebido: 16/03/2021 | Revisado: 23/03/2021 | Aceito: 28/03/2021 | Publicado: 06/04/2021

Juliana de Souza Pereira

ORCID: https://orcid.org/0000-0003-3107-8487 Universidade Federal Rural de Pernambuco, Brasil E-mail: julianasouza.uni@gmail.com

Maurício Luiz de Mello Vieira Leite

ORCID: https://orcid.org/0000-0003-4241-241X Universidade Federal Rural de Pernambuco, Brasil

E-mail: nopalea21@yahoo.com.br

Anderson Barbosa Cavalcante

ORCID: https://orcid.org/0000-0001-5079-4759 Universidade Federal Rural de Pernambuco, Brasil E-mail: andersonbarcante@outlook.com

Leandro Ricardo Rodrigues de Lucena

ORCID: https://orcid.org/0000-0001-6985-7668 Universidade Federal Rural de Pernambuco, Brasil E-mail: leandroricardo_est@yahoo.com.br

Mirna Clarissa Rodrigues de Almeida

ORCID: https://orcid.org/0000-0001-7927-1329

Universidade Federal Rural de Pernambuco, Brasil E-mail: mirna-clarissa@hotmail.com

Antônio Dennys Melo de Oliveira

ORCID: https://orcid.org/0000-0002-6370-8124 Universidade Federal Rural de Pernambuco, Brasil E-mail: dennysmelo15@gmail.com

Álefe Chagas de Lima Costa

ORCID: https://orcid.org/0000-0001-7021-4037 Universidade Federal Rural de Pernambuco, Brasil E-mail: alefechagas@outlook.com

\begin{abstract}
Resumo
Objetivou-se avaliar o crescimento de palma forrageira (Nopalea cochenillifera clone Doce Gigante), em diferentes métodos de fracionamento do cladódio. $\mathrm{O}$ delineamento experimental utilizado foi o inteiramente casualizado com cinco tratamentos, sendo que cada tratamento foi formado por 15 repetições. No tratamento testemunha o cladódio foi plantado inteiro pelo método convencional, no segundo e terceiro tratamento os cladódios foram divididos ao meio $(1 / 2)$ em sentido horizontal e vertical, respectivamente. No quarto tratamento as mudas foram compostas de um quarto (1/4) do cladódio e para o quinto tratamento os segmentos foram constituídos com dimensões de $6,0 \mathrm{~cm}$ de altura por $4,0 \mathrm{~cm}$ de largura. Durante o experimento foram avaliados o número de cladódios por planta, comprimento, largura e espessura dos cladódios, utilizando um paquímetro digital e trena métrica. A análise estatística foi realizada com o Software R-project 2.13.1. Em relação ao comprimento, largura e espessura do cladódio foi observado efeito significativo entre os tratamentos, de modo que os cladódios originados dos tratamentos com meio (1/2) cladódio com corte vertical foram superiores aos demais tratamentos. Observou-se que as plantas que tiveram origem a partir do cladódio inteiro apresentaram maior peso por planta. A técnica de multiplicação por meio de segmentos obtidos do cladódio apresenta-se como uma alternativa viável para os sistemas de produção animal no Semiárido brasileiro, para o cultivo de palma forrageira clone Doce Gigante. Os cladódios seccionados ao meio no sentido vertical podem ser utilizados no plantio de palma forrageira clone Doce Gigante.
\end{abstract}

Palavras-chave: Forragem; Fracionamento de cladódio, Nopalea cochenillifera.

\begin{abstract}
The objective of this study was to evaluate the growth of forage cactus (Nopalea cochenillifera clone Doce Gigante), using different cladode fractionation methods. The experimental design used was completely randomized with five treatments, and each treatment was formed by 15 repetitions. In the control treatment the cladode was planted whole by the conventional method, in the second and third treatment the cladodes were divided in half $(1 / 2)$ in a horizontal and vertical direction, respectively. In the fourth treatment the seedlings were composed of a fourth $(1 / 4)$ of the cladode
\end{abstract}


and for the fifth treatment the segments were constituted with dimensions of $6.0 \mathrm{~cm}$ in height and $4.0 \mathrm{~cm}$ in width. During the experiment, the number of cladodes per plant, length, width and thickness of the cladodes were evaluated, using a digital caliper and metric measuring tape. The statistical analysis was performed with the R-project 2.13.1 software. In relation to the length, width and thickness of the cladode, a significant effect was observed between the treatments, so that the cladodes originated from the treatments with half $(1 / 2)$ cladode with vertical cut were superior to the other treatments. It was observed that the plants that originated from the entire cladode had higher weight per plant. The multiplication technique by means of segments obtained from the cladode presents itself as a viable alternative for animal production systems in the Brazilian Semiarid, for the cultivation of forage cactus clone Doce Gigante. Cladodes cut in half vertically can be used for planting forage cactus clone Doce Gigante.

Keywords: Forrage; Cladode fractionation; Nopalea cochenillifera.

\section{Resumen}

El objetivo de este estudio fue evaluar el crecimiento de palma forrajera (Nopalea cochenillifera clon Doce Gigante), utilizando diferentes métodos de fraccionamiento del cladodio. El diseño experimental utilizado fue completamente al azar con cinco tratamientos, y cada tratamiento estuvo formado por 15 repeticiones. En el tratamiento control el cladodio se plantó entero por el método convencional, en el segundo y tercer tratamiento los cladodios se dividieron por la mitad $(1 / 2)$ en dirección horizontal y vertical, respectivamente. En el cuarto tratamiento, las plántulas se componían de un cuarto $(1 / 4)$ del cladodio y para el quinto tratamiento se constituían los segmentos con dimensiones de $6.0 \mathrm{~cm}$ de alto y $4.0 \mathrm{~cm}$ de ancho. Durante el experimento, se evaluó el número de cladodios por planta, largo, ancho y grosor de los cladodios, utilizando un calibre digital y una cinta métrica métrica. El análisis estadístico se realizó con el software R-project 2.13.1. En relación al largo, ancho y espesor del cladodio, se observó un efecto significativo entre los tratamientos, de manera que los cladodios originados a partir de los tratamientos con cladodio medio $(1 / 2)$ con corte vertical fueron superiores a los demás tratamientos. Se observó que las plantas que se originaron en todo el cladodio tuvieron mayor peso por planta. La técnica de multiplicación mediante segmentos obtenidos del cladodio se presenta como una alternativa viable para los sistemas de producción animal en el Semiárido brasileño, para el cultivo del clon de palma forrajera Doce Gigante. Los cladodios cortados por la mitad verticalmente se pueden utilizar para plantar el clon de palma forrajera Doce Gigante.

Palabras clave: Forraje; Fraccionamiento del cladodio; Nopalea cochenillifera.

\section{Introdução}

A pecuária de ruminantes tem se constituído em uma das principais atividades econômicas no Semiárido brasileiro $(\mathrm{SAB})$, porém negativamente afetada pela disponibilidade sazonal de forragens, principalmente devido às variações climáticas em termos de precipitação pluvial e evapotranspiração (Pereira, Leite, Cavalcante \& Lucena, 2018; Rocha, Voltolini \& Gava, 2017).

Fatores como a baixa qualidade e disponibilidade das forragens durante o ano, o manejo e aproveitamento inadequado das pastagens, o reduzido uso de tecnologias resilientes em ambiente semiárido, além da baixa capacidade de suporte forrageiro das pastagens nativas, vêm ocasionando baixa produtividade bioeconômica dos rebanhos no SAB (Leite, Silva, Andrade, Pereira \& Ramos, 2014).

Tal fato demanda o cultivo de espécies forrageiras tolerantes ao déficit hídrico por longos períodos e que sejam eficientes no uso de água, para minimizar a falta de forragem na estação seca e contribuir com a sustentabilidade da pecuária nesta região.

Neste cenário, a palma forrageira é uma das principais alternativas para os sistemas de produção de carne e leite do SAB e está presente na base da alimentação dos rebanhos (Souza, Nascimento, Figueredo, Nápoles \& Andrade, 2019; Cavalcante, Santos, Silva, Fagundes \& Silva, 2014). Isso se deve, principalmente, ao elevado rendimento forrageiro e alta adaptação às condições climáticas locais, em virtude de suas características anatômicas, morfofisiológicas e bioquímicas, que possibilitam a essa cultura uma maior eficiência na absorção e utilização de água (Azevedo, Silva, Bruno \& Quirino, 2013; Cushman, 2001).

No entanto, houve uma considerável redução dos palmais durante os últimos anos, causada principalmente pela ação da cochonilha-do-carmim (Dactylopius opuntiae Cockerell), considerada a principal praga da palma forrageira no Nordeste brasileiro (Lopes, Costa, Cordeiro Júnior \& Brito, 2013; Lima et al., 2011). 
Uma possibilidade tecnológica, para contornar esse problema, é o plantio de genótipos resistentes à praga, a exemplo dos clones Doce Miúda, Doce Gigante (Nopalea cochenillifera Salm Dyck) e Orelha de Elefante Mexicana (Opuntia stricta Haw) (Santos, Silva, Dubeux Júnior, Lira, \& Silva, 2013). Porém, os preços elevados dos cladódios em épocas de estiagem (Almeida, Silva, Araújo, Oliveira \& Leite, 2011), além da baixa disponibilidade em relação à demanda de material vegetativo de espécies resistentes, podem dificultar e inviabilizar economicamente a produção de palma forrageira em larga escala.

A necessidade de grandes quantidades de cladódios no plantio tradicional da palma, de forma clonal natural, torna-se um sério problema. A limitação desse sistema de propagação pode ser superada pela utilização de novas tecnologias atualmente disponíveis (Vasconcelos, Lira, Cavalcanti, Santos \& Willadino, 2009), dentre elas a utilização da micropropagação por seccionamento e/ou segmento de cladódio. Essa técnica promove a formação de indivíduos geneticamente similares a partir de células, órgão ou fragmentos de uma planta matriz (Silva, 2017).

O método de propagação por fracionamento vem sendo estudado recentemente (Lopes et al., 2013), sendo possível produzir várias plantas de palma com apenas um cladódio, diferentemente do método de plantio tradicional, no qual um cladódio dá origem a apenas uma nova planta (Cavalcante, Leite, Pereira \& Lucena, 2017). Sendo assim, a técnica de fracionamento do cladódio pode ser considerada uma proposta promissora e relevante para o futuro dos sistemas de produção de palma, com viabilidade econômica e baixo impacto ambiental. Além de propiciar aumento na oferta de material vegetativo de alta qualidade para o plantio, pode reduzir os custos com a aquisição dos cladódios, o que aumenta consideravelmente a eficiência e sustentabilidade dos sistemas de produção animal no SAB.

Considerando-se a importância da palma forrageira para a sustentabilidade dos sistemas de produção de ruminantes no $\mathrm{SAB}$, as dificuldades na aquisição de material vegetativo resistente a cochonilha-do-carmim e os escassos estudos sobre diferentes métodos de propagação vegetativa, objetivou-se avaliar o crescimento de Nopalea cochenillifera clone Doce Gigante, em função do tipo de segmento adotado no fracionamento dos cladódios como método propagativo.

\section{Metodologia}

A pesquisa foi realizada na área experimental do Grupo de Estudos em Forragicultura (GEFOR), Unidade Acadêmica de Serra Talhada, Universidade Federal Rural de Pernambuco (UAST/UFRPE), microrregião do Sertão do Pajeú (Altitude: 429 m, latitude: $7^{\circ} 59^{\prime} 10^{\prime}$ S e longitude: $38^{\circ} 17^{\prime} 47^{\prime \prime}$ O). O clima da região segundo a classificação de Köppen é caracterizado como BSwh', semiárido quente e seco, pluviosidade média anual de $632 \mathrm{~mm}^{\text {ano }}{ }^{-1}$, temperatura do ar média anual de $26{ }^{\circ} \mathrm{C}$ e umidade relativa média do ar de 60\% (Leite et al., 2020a).

O delineamento experimental utilizado foi o inteiramente casualizado com cinco tratamentos, sendo que cada tratamento foi formado por 15 repetições. Os tratamentos constituíram-se por diferentes métodos de fracionamento ou segmentação do cladódio de palma forrageira (Nopalea cochenillifera), clone Doce Gigante, resistente à cochonilha-docarmim, conforme Pereira et al. (2018).

No tratamento testemunha, o cladódio não foi fracionado, sendo plantado inteiro pelo método convencional (T1). No segundo tratamento (T2), o cladódio foi dividido ao meio (1/2) com um corte no sentido horizontal. No terceiro tratamento (T3), o cladódio também foi seccionado ao meio (1/2), porém, no sentido vertical. No quarto tratamento (T4), as mudas foram compostas de um quarto (1/4) do cladódio inteiro. Por fim, para o quinto tratamento (T5), os segmentos foram constituídos com dimensões de 6,0 cm de comprimento por 4,0 cm de largura, com no mínimo duas aréolas em cada segmento (Figura 1). 
Figura 1. a) Cladódio inteiro (T1); b) 1/2 do cladódio com corte horizontal (T2); c) 1/2 do cladódio com corte vertical (T3); d) 1/4 do cladódio (T4); e) segmentos de cladódio com 6,0 x 4,0 cm (T5).

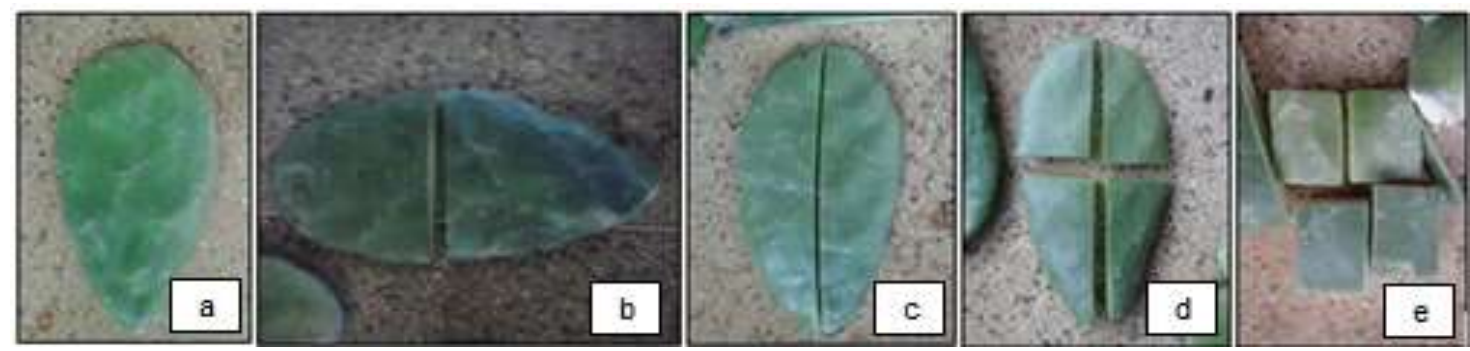

Fonte: Pereira et al. (2018).

Todas as mudas utilizadas no experimento passaram por processo de emurchecimento natural e cura em ambiente sombreado por um período de três dias, não sendo utilizada nenhuma substância fungicida ou bactericida antes do plantio. Em seguida, as mudas foram plantadas em sacos de poliéster com capacidade de 2,0 kg, contendo uma mistura 2:1 de solo e esterco bovino curtido, respectivamente.

A análise química do solo utilizado no ensaio, classificado como Cambissolo Háplico Ta Eutrófico típico (Empresa Brasileira de Pesquisa Agropecuária [EMBRAPA], 2013), coletado na área experimental na profundidade de 0 a $20 \mathrm{~cm}$, foi realizada pelo Laboratório de Fertilidade do Solo do Instituto Agronômico de Pernambuco (IPA), possuindo os seguintes atributos de fertilidade: $\mathrm{pH}$ (água) $=6,80 ; \mathrm{P}($ extrator Mehlich $\mathrm{I})=40,0 \mathrm{mg} \mathrm{dm}{ }^{-3} ; \mathrm{K}^{+}, \mathrm{Ca}^{2+}, \mathrm{Mg}^{2+}$ e $\mathrm{Al}^{3+}$ de $0,45,5,50,1,6$ e 0,0 $\mathrm{cmol}_{\mathrm{c}} \mathrm{dm}^{-3}$, respectivamente.

Os sacos com as mudas foram mantidos sobre o solo durante 93 dias, em local aberto e irrigados três vezes por semana, objetivando-se assegurar a sobrevivência das mudas. A água utilizada possuía condutividade elétrica de $0,03 \mathrm{dS} \mathrm{m}^{-1} \mathrm{e}$ razão de adsorção de sódio de 1,09 $\mathrm{mg} \mathrm{L}^{-1}$, sendo classificada por Sales, Lopes, Meireles, Chaves e Andrade (2014) como C1 (baixo risco de salinização) e S1 (baixo risco de sodificação), sem nenhuma restrição de uso agrícola.

Após o período de estabilização, as mudas foram transplantadas para vasos plásticos com capacidade de $21,19 \mathrm{dm}^{3}$, contendo o mesmo substrato utilizado nos sacos, devidamente identificados por tratamento e distribuídos na área experimental de forma aleatória. Nessa etapa, as mudas foram irrigadas uma vez por semana.

Vale salientar que durante todo o período experimental as mudas foram mantidas no campo sem a utilização de qualquer produto químico ou natural para controle de pragas ou doenças.

A primeira avaliação foi realizada aos 30 dias após o transplantio (DAT) e as avaliações seguintes foram realizadas, periodicamente, a cada 30 dias em um período de avaliação de três meses. Foram avaliados o número de cladódios por planta, comprimento, largura e espessura de cladódio, utilizando paquímetro digital e trena métrica.

No final do período experimental foi realizado o corte de todos os cladódios, para determinação da massa seca. Amostras de, aproximadamente, $600 \mathrm{~g}$ dos cladódios de cada tratamento, foram cortadas no sentido transversal e colocadas em bandejas de papelão. Determinou-se o peso seco da palma forrageira por meio de secagem do material em estufa de circulação forçada de ar a $65^{\circ} \mathrm{C}$ até peso constante, com posterior pesagem (Cavalcante et al., 2017).

A análise estatística foi realizada com o Software R-project 2.13.1. Os resultados das variáveis foram expressos pela média e desvio padrão. Além disso, foi realizada a análise de variância e as médias que apresentaram diferença foram comparadas entre si pelo teste de Tukey $(\mathrm{p}<0,05)$. 


\section{Resultados e Discussão}

Em relação a variável comprimento de cladódio de palma forrageira clone Doce Gigante em função da propagação por segmento de cladódio (Tabela 1), não foi observado diferença estatística nos tratamentos em relação aos dias após o transplantio (DAT). Mas, observa-se efeito significativo entre os tratamentos, de modo que os cladódios originados do $1 / 2$ cladódio com corte vertical (T3) foram superiores aos demais tratamentos, nos três períodos avaliados. Verificou-se similaridade do T3 aos cladódios originados do segmento de cladódio 6 x 4 cm (T5) aos 60 e 90 DAT, sendo ambos superiores aos demais tratamentos. Ou seja, após 60 DAT, T3 e T5 demonstraram um comportamento semelhante.

Tabela 1. Evolução do comprimento e largura de cladódio de palma forrageira clone Doce Gigante em função da propagação por segmentos de cladódio, expresso por média \pm desvio padrão.

\begin{tabular}{|c|c|c|c|c|c|c|}
\hline \multirow{2}{*}{ DAT } & \multicolumn{5}{|c|}{ Comprimento de cladódio $(\mathrm{cm})$} & \multirow{2}{*}{ p-valor } \\
\hline & T1 & $\mathbf{T 2}$ & T3 & T4 & T5 & \\
\hline 30 & $22,8 \pm 5,1 b$ & $22,4 \pm 4,2 b$ & $26,5 \pm 4,7 \mathrm{a}$ & $21,1 \pm 5,0 b$ & $21,0 \pm 4,4 b$ & $<0,0001$ \\
\hline 60 & $23,1 \pm 5,2 b$ & $23,2 \pm 4,2 b$ & $27,1 \pm 4,6 \mathrm{a}$ & $22,1 \pm 5,3 b$ & $24,0 \pm 3,9 \mathrm{ab}$ & $<0,0001$ \\
\hline 90 & $23,4 \pm 5,2 b$ & $23,5 \pm 4,4 b$ & $27,3 \pm 4,5 \mathrm{a}$ & $22,3 \pm 5,3 b$ & $24,8 \pm 3,9 \mathrm{ab}$ & $<0,0001$ \\
\hline p-valor & 0,235 & 0,776 & 0,653 & 0,336 & 0,460 & \\
\hline \multirow{2}{*}{ DAT } & \multicolumn{5}{|c|}{ Largura de cladódio $(\mathrm{cm})$} & \multirow{2}{*}{ p-valor } \\
\hline & T1 & $\mathbf{T 2}$ & T3 & T4 & T5 & \\
\hline 30 & $9,1 \pm 1,8 \mathrm{a}$ & $7,9 \pm 1,6 b$ & $10,1 \pm 1,7 \mathrm{a}$ & $7,0 \pm 1,4 \mathrm{~b}$ & $5,3 \pm 1,3 \mathrm{c}$ & $<0,0001$ \\
\hline 60 & $9,7 \pm 1,8 \mathrm{ab}$ & $8,5 \pm 1,8 \mathrm{bc}$ & $10,6 \pm 1,7 \mathrm{a}$ & $7,6 \pm 1,4 \mathrm{c}$ & $6,3 \pm 1,3 \mathrm{~d}$ & $<0,0001$ \\
\hline 90 & $9,8 \pm 1,9 \mathrm{ab}$ & $8,8 \pm 1,8 \mathrm{bc}$ & $10,8 \pm 1,8 \mathrm{a}$ & $7,8 \pm 1,4 \mathrm{c}$ & $6,5 \pm 1,2 d$ & $<0,0001$ \\
\hline p-valor & 0,457 & 0,554 & 0,342 & 0,628 & 0,354 & \\
\hline
\end{tabular}

T1 = Cladódio inteiro, T2 = 1/2 cladódio, corte horizontal, T3 = 1/2 cladódio, corte vertical, T4 = 1/4 cladódio, T5 = Frações $6 \times 4 \mathrm{~cm}$. DAT = Dias Após o Transplantio. Médias seguidas por letras minúsculas distintas na linha diferem entre si pelo teste Tukey. Fonte: Autores.

Além disso, o comprimento de cladódio com corte horizontal (T2) foi inferior ao cladódio com corte vertical (T3), decorrente da menor superfície de contato com a luz solar. Tal resultado também foi observado mesmo com cladódios que não sofreram fracionamento, ou seja, com aqueles plantados pelo método convencional (T1). Vale salientar que apesar de maior área para fotossíntese do que os demais tratamentos, no T1 a emissão de cladódios foi maior (Tabela 3), e por isso a demanda metabólica da planta para suprir o desenvolvimento dos cladódios emitidos foi maior, o que, portanto, resultou em menor comprimento dos cladódios se comparado ao tratamento 3 (T3) (Pereira et al., 2018).

Os resultados dessa pesquisa corroboram com as evidências observadas por Peixoto et al. (2018), ao afirmaram que cladódios expostos a maior luminosidade e temperatura do ar apresentam uma potencialização no processo de fotossíntese e consequentemente na emissão de cladódios e no crescimento dos mesmos.

O fato dos cladódios originados da fração 6 × $4 \mathrm{~cm}$ (T5) não diferirem estatisticamente dos cladódios originados do $1 / 2$ cladódio com corte vertical (T3) aos 60 e 90 DAT, sinaliza a ocorrência de um crescimento direcionado em resposta ao estresse sofrido pela alta diminuição de sua área fotossintética, o que exigiu da planta o aumento dessa área, porém sem aumento na perda de umidade para atmosfera, resultado obtido através do alongamento vertical do cladódio (Peixoto et al., 2018).

Avaliando a largura de cladódio de palma forrageira em função da propagação por segmentos do cladódio (Tabela 1), verifica-se que os cladódios originados do 1/2 cladódio com corte vertical (T3) foram superiores aos demais tratamentos, porém 
não diferiram dos cladódios que tiveram origem a partir do cladódio inteiro (T1), nos três períodos avaliados. Isto é, T3 e T1 demonstraram um comportamento semelhante em relação à largura de cladódio.

Segundo Rocha, Voltolini e Gava (2017), a estrutura morfológica do cladódio pode influenciar o crescimento e as respostas produtivas da palma, o que pode ser observado na Tabela 1. A largura dos cladódios gerados a partir do segmento $6 \mathrm{x}$ $4 \mathrm{~cm}$ (T5) foi inferior aos demais tratamentos nos três períodos avaliados, possivelmente porque de todos os tratamentos esse é o de menor área fotossintética, menor reserva de fotoassimilados, o que resulta em um menor potencial no desenvolvimento dos cladódios. Ademais o material vegetativo utilizado nesse tratamento (T5) apresentava menor quantidade de aréolas, que por sua vez resulta em uma menor emissão de raiz e de novos brotos nos períodos iniciais após o plantio. Portanto, a associação de tais fatores, contribui diretamente em uma menor produção de carboidratos essenciais para a planta, fato que exerce influência negativa direta no crescimento da planta (Pereira et al., 2018).

Em relação à espessura de cladódio (Tabela 2), observa-se aos 30 DAT que os cladódios originados do 1/2 cladódio com corte vertical (T1) foram superiores aos demais, porém foram similares aos cladódios originados a partir do 1/4 de cladódio (T4). Aos 60 e 90 DAT não houve diferença significativa $(p>0,05)$ entre os tratamentos, indicando que a partir dos 60 DAT o fracionamento do cladódio não influenciou na espessura dos cladódios emitidos.

Os cladódios mais jovens são menos eficientes no controle da perda de água em comparação aos cladódios maduros (Donato, Borém \& Rodrigues, 2020). Os movimentos de abertura e fechamento estomáticos são influenciados, dentre outros fatores, pela temperatura do ar e do cladódio, intensidade de luz, concentração interna de $\mathrm{CO}_{2}$, umidade do ar, teor de água no solo, status hídrico e nutricional da planta e/ou cladódio, idade do cladódio e genótipo (Buckley, 2017).

Scalisi, Morandi, Inglese e Bianco (2016) reportaram que o conteúdo de água do solo promove interferência na espessura dos cladódios da palma forrageira, a qual aumenta sob irrigação e diminui quando a planta é submetida ao déficit hídrico. Pode-se inferir que a partir dos 60 DAT as plantas de todos os tratamentos avaliados estavam túrgidas e com absorção satisfatória de água. Ou seja, essas plantas não estavam sob déficit hídrico e seus cladódios não precisaram reduzir sua transpiração, resultando na similaridade da espessura de cladódio entre os tratamentos. Essa hidratação satisfatória das plantas é favorável para o crescimento da palma forrageira.

Tabela 2. Evolução da espessura de cladódio de palma forrageira clone Doce Gigante em função da propagação por segmentos de cladódio, expresso por média \pm desvio padrão.

\begin{tabular}{|c|c|c|c|c|c|c|}
\hline \multirow{2}{*}{ DAT } & \multicolumn{5}{|c|}{ Espessura de cladódio (cm) } & \multirow{2}{*}{ p-valo } \\
\hline & T1 & T2 & T3 & T4 & T5 & \\
\hline 30 & $1,0 \pm 0,2 b c$ & $0,9 \pm 0,1 \mathrm{~cd}$ & $1,1 \pm 0,2 \mathrm{a}$ & $1,1 \pm 0,2 \mathrm{ab}$ & $0,8 \pm 0,1 \mathrm{~d}$ & $<0,0001$ \\
\hline 60 & $1,1 \pm 0,3$ & $1,2 \pm 0,2$ & $1,1 \pm 0,3$ & $1,0 \pm 0,4$ & $0,9 \pm 0,4$ & 0,094 \\
\hline 90 & $1,1 \pm 0,3$ & $1,3 \pm 0,4$ & $1,2 \pm 0,5$ & $1,1 \pm 0,4$ & $0,9 \pm 0,4$ & 0,150 \\
\hline
\end{tabular}

T1 = Cladódio inteiro, T2 = 1/2 cladódio, corte horizontal, T3 = 1/2 cladódio, corte vertical, T4=1/4 cladódio, T5 = Frações $6 x 4 \mathrm{~cm}$. DAT = Dias Após o Transplantio. Médias seguidas por letras distintas na linha diferem entre si pelo teste Tukey. Fonte: Autores.

Quando se leva em consideração comprimento, largura e espessura de cladódio aos 90 DAT, os cladódios que tiveram origem a partir do $1 \frac{1}{2}$ cladódio com corte vertical (T3) foi o único tratamento que se sobressaiu nas três variáveis ao mesmo tempo.

Os resultados obtidos para as variáveis supracitadas foram similares aos valores médios obtidos por Cavalcante et al. (2014), que obtiveram respectivamente dados médios para comprimento de 22,02 cm, largura de $9,55 \mathrm{~cm}$ e espessura de 2,32 
cm para os cladódios do clone Doce Miúda ( $N$. cochenillifera). Vale ressaltar que os autores citados avaliaram plantas com 24 meses após o plantio e adubadas com esterco e adubo mineral.

Os resultados do pressente estudo em relação às características morfométricas do cladódio estão em conformidade com Silva et al. (2010), que avaliaram cladódios de cinquenta clones de palma forrageira estabelecidos em palmais de cinco anos na região de Caruaru $-\mathrm{PE}$.

Observa-se que nos três períodos avaliados, o segmento 6 x $4 \mathrm{~cm}$ (T5) emitiu um menor número de cladódios, enquanto as plantas originadas do cladódio inteiro (T1) mostraram-se superiores em relação ao quantitativo de cladódios (Tabela 3). Salienta-se que um cladódio inteiro, por ter uma superfície maior, apresenta uma maior quantidade de aréolas, estruturas que equivalem as gemas axilares, e que em condições ambientais adequadas podem dar origem a novos cladódios (Pereira et al., 2018).

Tabela 3. Evolução do número de cladódios por planta de palma forrageira clone Doce Gigante em função da propagação por segmentos de cladódio, expresso por média \pm desvio padrão.

\begin{tabular}{lrrrrrr}
\hline \multirow{2}{*}{ DAT } & \multicolumn{7}{c}{ Número de cladódio } & \multirow{2}{*}{ p-valor } \\
\cline { 2 - 6 } & T1 & T2 & T3 & T4 & T5 & \\
\hline $\mathbf{3 0}$ & $4,2 \pm 1,01 \mathrm{a}$ & $3,7 \pm 0,82 \mathrm{ab}$ & $3,3 \pm 0,95 \mathrm{~b}$ & $2,4 \pm 0,88 \mathrm{c}$ & $1,1 \pm 0,28 \mathrm{~d}$ & $<0,0001$ \\
$\mathbf{6 0}$ & $4,3 \pm 1,03 \mathrm{a}$ & $3,3 \pm 1,18 \mathrm{~b}$ & $3,7 \pm 1,37 \mathrm{ab}$ & $3,3 \pm 0,89 \mathrm{~b}$ & $1,7 \pm 0,75 \mathrm{c}$ & $<0,0001$ \\
$\mathbf{9 0}$ & $5,0 \pm 0,81 \mathrm{a}$ & $3,7 \pm 1,53 \mathrm{~b}$ & $3,9 \pm 1,44 \mathrm{~b}$ & $4,1 \pm 1,45 \mathrm{ab}$ & $2,3 \pm 0,63 \mathrm{c}$ & $<0,0001$ \\
\hline
\end{tabular}

T1 = Cladódio inteiro, T2 = 1/2 cladódio, corte horizontal, T3 = 1/2 cladódio, corte vertical, T4 = 1/4 cladódio, T5 = Frações $6 \times 4 \mathrm{~cm}$. DAT = Dias Após o Transplantio. Médias seguidas por letras distintas na linha diferem entre si pelo teste Tukey. Fonte: Autores.

O número total de cladódios é uma importante característica da planta, pois apresenta correlação alta $(\mathrm{r}=0,9438)$ com a produção de fitomassa (Pinheiro et al., 2014). Segundo Leite et al. (2020b), um dos fatores determinantes da elevada produção de biomassa na palma forrageira é a eficiência fotossintética, com absorção e uso da radiação solar na fotossíntese, função realizada pelos cladódios nos cactos.

Em relação à altura de planta do clone Doce Gigante aos 90 DAT (Figura 2), verifica-se superioridade dos cladódios originados do 1/2 cladódio com corte vertical (T3) e dos cladódios inteiros (T1) em comparação aos 1/2 cladódio com corte horizontal (T2) e segmento de cladódio 6 x $4 \mathrm{~cm}$ (T5). A maior quantidade de reserva energética e fitohormônios do material vegetativo, presentes nos cladódios mais vigorosos (T1 e T3), estimulam a divisão e elongação celular, proporcionado plantas mais altas (Pereira et al., 2018). 
Figura 2. Altura de planta de palma forrageira clone Doce Gigante em função da propagação por segmentos de cladódio, aos 90 dias após o transplantio.

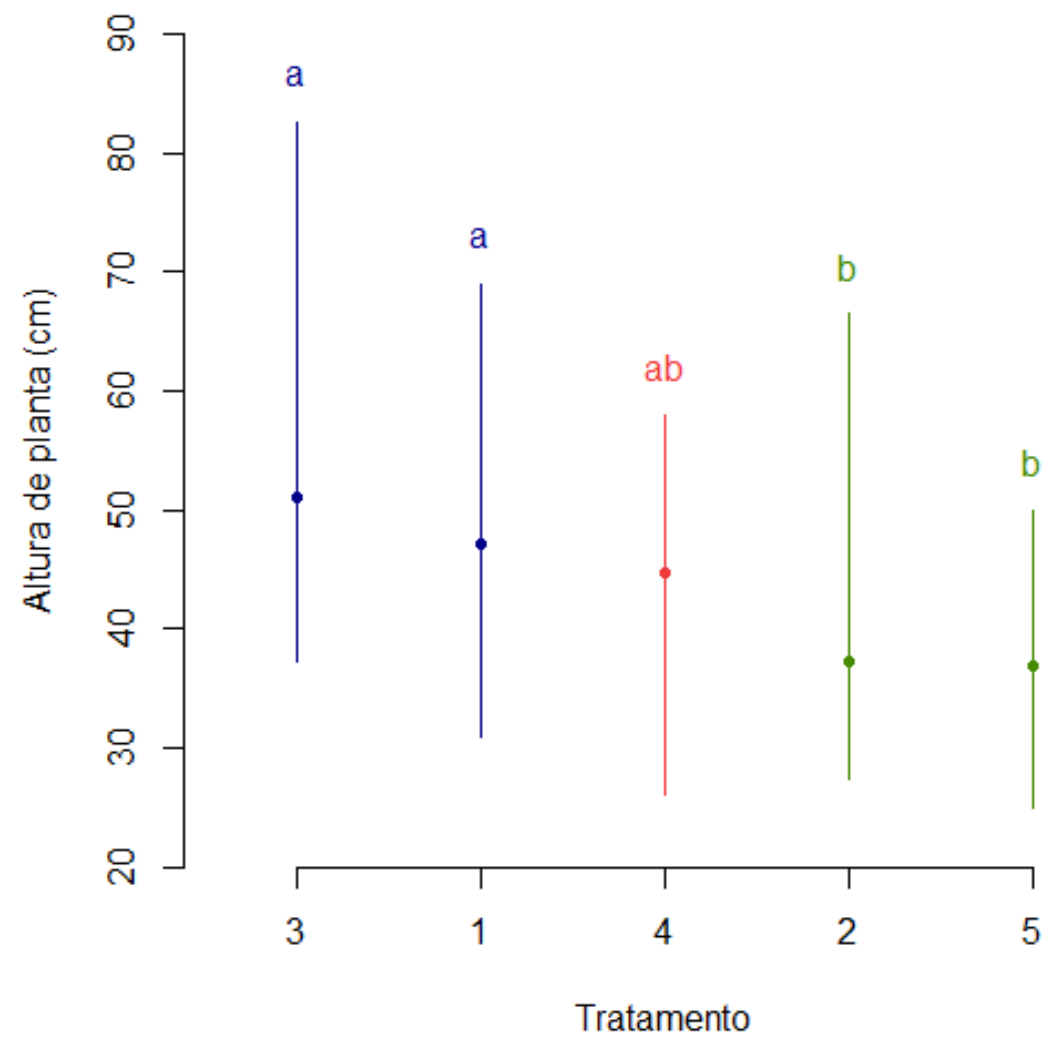

Tratamento 1 (T1) = Cladódio inteiro, Tratamento $2(\mathrm{~T} 2)=1 / 2$ cladódio, corte horizontal, Tratamento 3 (T3) = 1/2 cladódio, corte vertical, Tratamento $4(\mathrm{~T} 4)=1 / 4$ cladódio, Tratamento $5(\mathrm{~T} 5)$ = Frações $6 \times 4 \mathrm{~cm}$. Médias seguidas por letras minúsculas distintas diferem entre si pelo teste Tukey. Fonte: Autores.

As plantas originadas do cladódio inteiro (T1) e 1/2 cladódio com corte vertical (T3) apresentaram maior peso seco, embora não se diferenciaram da planta surgida do 1/2 cladódio com corte horizontal (T2) (Figura 3). 
Figura 3. Média de peso seco (g) por planta de palma forrageira clone Doce Gigante em função da propagação por segmentos de cladódio, aos 90 dias após o transplantio

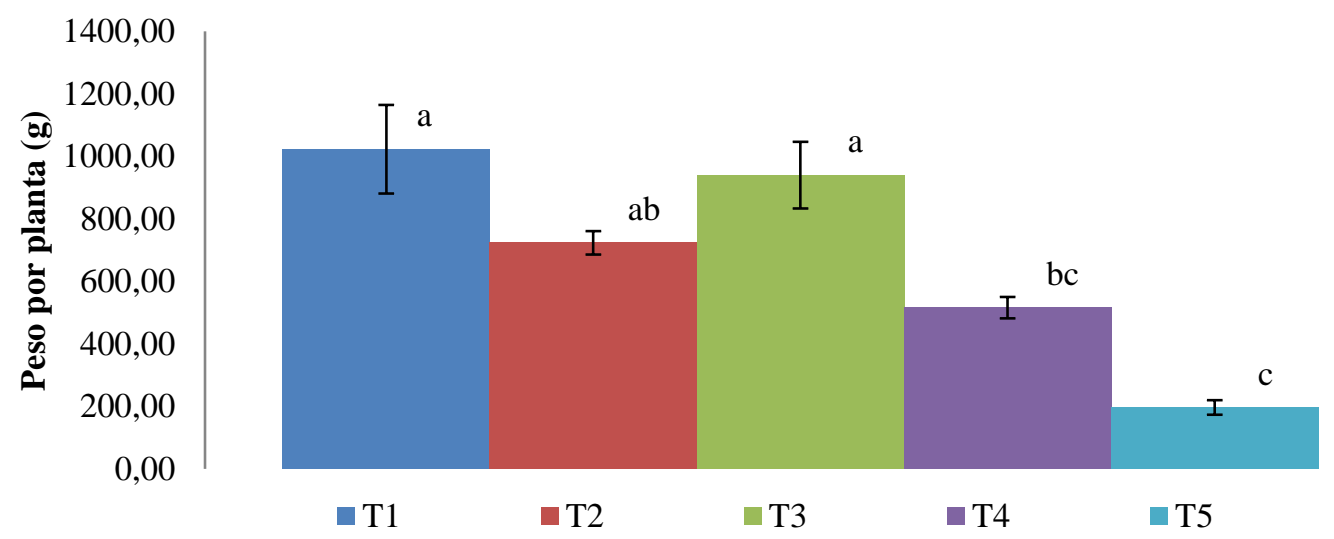

Tratamento 1 (T1) = Cladódio inteiro, Tratamento $2(\mathrm{~T} 2)=1 / 2$ cladódio, corte horizontal, Tratamento 3 (T3) = 1/2 cladódio, corte vertical, Tratamento $4(\mathrm{~T} 4)=1 / 4$ cladódio, Tratamento $5(\mathrm{~T} 5)=$ Frações $6 \mathrm{x} 4 \mathrm{~cm}$. Médias seguidas por letras minúsculas distintas diferem entre si pelo teste Tukey. Fonte: Autores.

Peixoto et al. (2018) observaram que cladódios com maior área exposta a luminosidade apresentaram produção de massa verde 33,03\% superiores a tratamentos onde os cladódios sofriam interferência do sombreamento. O que reforça o fato de quanto maior a exposição do cladódio à luz, o resultado pode ser notado em uma potencialização no seu crescimento e desenvolvimento, o que neste caso foi observado no efeito no peso das plantas de palma forrageira clone Doce Gigante submetidos a diferentes métodos de fracionamentos dos cladódios.

Quando se leva em consideração as seis variáveis analisadas (comprimento, largura, espessura, número de cladódio, altura de planta e peso seco da planta), aos 90 DAT, as plantas originadas a partir do 1/2 cladódio com corte vertical (T3) se sobressaem em quatro variáveis, com exceção de número de cladódios por planta, com superioridade do cladódio inteiro (T1) e espessura de cladódio, pois não houve diferença entre os tratamentos. Ressalta-se, ainda, que um cladódio cortado verticalmente ao meio gera duas mudas, e consequentemente duas plantas, sendo uma vantagem comparativa em relação ao método tradicional (T1).

Fundamentado nos resultados verificados nessa pesquisa, até os 90 DAT, o cladódio de palma forrageira clone Doce Gigante cortado verticalmente ao meio (T3) pode ser indicado para o plantio dessa cultura. Entretanto, mais estudos são necessários para avaliar se as diferenças permanecem entre os tratamentos em função do tempo de desenvolvimento da palma forrageira.

\section{Conclusão}

A técnica de multiplicação por meio de segmentos obtidos do cladódio apresenta-se como uma alternativa viável para o cultivo de palma forrageira clone Doce Gigante nos sistemas de produção animal do Semiárido brasileiro.

Os cladódios seccionados ao meio no sentido vertical podem ser utilizados no plantio de palma forrageira clone Doce Gigante.

Plantas de palma forrageira clone Doce Gigante provenientes de cladódios não fracionados apresentam maior número de cladódios por planta. 


\section{Referências}

Almeida, A. A., Silva, R. A., Araújo, W. L., Oliveira, A. V. B., \& Leite, D. T. (2011). Problemas fitossanitários causados pela cochonilha do carmim a palma forrageira no Cariri Ocidental paraibano. Revista Verde de Agroecologia e Desenvolvimento Sustentável, 6(3), 98-108. http://www.gvaa.com.br/revista/index.php/RVADS/article/view/743

Azevedo, C. F., Silva, K. R. G., Bruno, R. L. A., \& Quirino, Z. G. M. (2013). Morfoanatomia vegetativa de Opuntia brasiliensis (Willd) Haw / Vegetative morphology and anatomy of Opuntia brasiliensis (Willd) Haw. Revista Ambiência, 9(1), 73-82. https://doi.org/10.5777/ambiencia.2013.01.05

Buckley, T. N. (2017). Modeling stomatal conductance. Plant Physiology, 174(2), 572-582. http://dx.doi.org/10.1104/ pp.16.01772.

Cavalcante, A. B., Leite, M. L. M. V., Pereira, J. S., \& Lucena, L. R. R. (2017). Crescimento de palma forrageira em função da cura de segmentos dos cladódios. Tecnologia \& Ciência Agropecuária, 11(5), 15-20. http://revistatca.pb.gov.br/edicoes/volume-11-2017/v-11-n-5-dezembro-2017/03-crescimentode-palma-forrageira.pdf

Cavalcante, L. A. D., Santos, G. R. A., Silva, L. M., Fagundes, J. L., \& Silva, M. A. (2014). Respostas de genótipos de palma forrageira a diferentes densidades de cultivo. Pesquisa Agropecuária Tropical, 44(4), 424-433. https://doi.org/10.1590/s1983-40632014000400010

Cushman, J. C. (2001). Update on Crassulacean Acid Metabolism Crassulacean Acid Metabolism . A Plastic Photosynthetic Adaptation to Arid Environments 1. American Society of Plant Biologists, 127(December), 1439-1448. https://doi.org/10.1104/pp.010818.plants

Donato, S. L. R., Borém, A. \& Rodrigues, M. G. V (2020). Palma forrageira do plantio à colheita. EPAMIG.

Empresa Brasileira de Pesquisa Agropecuária. Centro Nacional de Pesquisas de Solos. Sistema Brasileiro de Classificação de Solos. 3. ed. Brasília: Embrapa Solos, 2013. 353 p.

Leite, M. L. M. V., Silva, D. S., Andrade, A. P., Pereira, W. E., \& Ramos, J. P. F. (2014). Caracterização da produção de palma forrageira no Cariri paraibano, Revista Caatinga, 27(2), 192-200. https://periodicos.ufersa.edu.br/index.php/caatinga/article/view/2830/pdf_128

Leite, M. L. M. V., Lucena, L. R. R., Oliveira, A. D. M., Costa, Á. C. L., Anjos, F. L. Q., Farias, I. M., Simões, V. J. L. P., \& Almeida, M. C. R. (2020a). Cladode area and weight of Nopalea cochenillifera clones as a function of morphometric characteristics. Journal of the Professional Association for Cactus Development, 21, 32-42. http://www.jpacd.org/jpacd/article/view/15

Leite, M. L. M. V., Oliveira, G. A., Lucena, L. R. R., Oliveira, A. D. M., Costa, Á. C. L., Anjos, F. L. Q., Silva, C. B., Farias, I. M. (2020b). Modelos matemáticos para estimativa de área e peso de cladódio de palma Doce Miúda. Research, Society and Development, 9(12), e47491211503. DOI: http://dx.doi.org/10.33448/rsd-v9i12.11503

Lima, M. S., Silva, D. M. P., Falcão, H. M., Ferreira, W. M., Silva, L. D., \& Paranhos, B. A. J. (2011). Predadores associados á Dactylopius opuntiae (Hemiptera: Dactylopiidae) em palma forrageira no estado de Pernambuco, Brasil. Revista Chilena de Entomologia, $36,51-54$.

Lopes, E. B., Costa, L. B., Cordeiro Júnior, A. F., \& Brito, C. H. (2013). Rendimento e aspectos fenológicos de espécies de palma forrageira em relação ao cultivo com dois tipos de cladódios. Tecnologia \& Ciência Agropecuária, 7(especial), 59-61. http://revistatca.pb.gov.br/edicoes/volume-07-2013/volume-7numero-5-dezembro- 2013/tca7512.pdf

Pereira, J. S., Leite, M. L. M. V., Cavalcante, A. B., \& Lucena, L. R. R. (2018). Crescimento inicial de Nopalea cochenillifera em função do fracionamento do cladódio. Revista Agropecuária Técnica, 39(2), 120-128. https://periodicos.ufpb.br/index.php/at/article/view/37995

Peixoto, M. J. A., Carneiro, M. S. S., Amorim, D. S., Edvan, R. L., Pereira, E. S., \& Costa, M. R. G. F. (2018). Características agronômicas e composição química da palma forrageira em função de diferentes sistemas de plantio. Archivos de Zootecnia, 67(260), 35-39. https://www.uco.es/ucopress/az/index.php/az/article/view/3489

Pinheiro, K. M., Silva, T. G. F., Carvalho, H. F. S., Santos, J. E. O., Morais, J. E. F., Zolnier, S., \& Santos, D. C. (2014). Correlações do índice de área do cladódio com características morfogênicas e produtivas da palma forrageira. Pesquisa Agropecuária Brasileira, 49(12), 939-947. http://dx.doi.org/10.1590/S0100-204X2014001200004

Rocha, R.S., Voltolini, T.V., \& Gava, C. A. T. (2017). Características produtivas e estruturais de genótipos de palma forrageira irrigada em diferentes intervalos de corte. Archivos de Zootecnia, 66, 365-373. https://www.uco.es/ucopress/az/index.php/az/article/view/2512

Sales, M. M., Lopes, F. B., Meireles, A. C. M., Chaves, L. C. G., \& Andrade, E. M. (2014). Variabilidade espacial e temporal da qualidade das águas em reservatório da região semiárida para fins de irrigação. Revista Brasileira de Agricultura Irrigada, 8(5), 411-421. 10.7127/rbai.v8n500221

Santos, D. C., Silva, M. C., Dubeux Júnior, J. C. B., Lira, M. A., \& Silva, R. M. (2013). Estratégias para uso de cactáceas em zonas semiáridas: novas cultivares e uso sustentável das espécies nativas. Revista Científica de Produção Animal. 15, 111-121. http://dx.doi.org/10.15528/2176-4158/rcpa.v15n2p111121

Scalisi, A., Morandi, B., Inglese, P. \& Bianco, R. L. (2016). Cladode growth dynamics in Opuntia ficus-indica under drought. Environmental and Experimental Botany, 122, 158-167.

Silva, M. M. A. Micropropagação da palma forrageira variedade Miúda em meio de cultura simplificado. (2017). Revista Tecnologia \& Ciência Agropecuária, 11(2), 25-29.

https://revistatca.pb.gov.br/edicoes/volume-11-2017/v-11-n-2-junho-2017/tca11205.pdf

Silva, N. G. M., Lira, M. A., Santos, M. V. F., Dubeux Júnior, J. C. B., Mello, A. C. L., \& Silva, M. C. (2010). Relação entre características morfológicas e produtivas de clones de palma-forrageira. Revista Brasileira de Zootecnia, 39(11), 2389-2397. https://doi.org/10.1590/S1516-35982010001100011

Souza, J. T. S., Nascimento, M. G. R., Figueiredo, J. P., Nápoles, F. A. M., \& Andrade, F. H. A. (2019). Caracterização Técnico-Produtiva Do Sistema De Cultivo De Palma Forrageira No Cariri Paraibano. Journal of Neotropical Agriculture, 6(2), 64-71. https://doi.org/10.32404/rean.v6i2.1683 
Research, Society and Development, v. 10, n. 4, e19210413951, 2021

(CC BY 4.0) | ISSN 2525-3409 | DOI: http://dx.doi.org/10.33448/rsd-v10i4.13951

Vasconcelos, A. G. V., Lira, M. A., Cavalcanti, V. L. B., Santos, M. V. F., \& Willadino, L. (2009). Seleção de clones de palma forrageira resistentes à cochonilha-do-carmim (Dactylopius sp.). Revista Brasileira de Zootecnia, 38(5), 827-831. http://dx.doi.org/10.1590/S1516-35982009000500007 